\title{
Jan Blommaert and the use of sociolinguistics: Critical, political, personal
}

\author{
B E N R A M T O N \\ King's College London, UK
}

On 7 January 2021, Jan Blommaert died aged 59, after a ten-month battle with cancer. He was an extraordinary person and a brilliant academic, and there have been a great many very moving personal accounts of how much Jan meant to the people he interacted with. I knew and worked with him for over twenty-five years, and during his protracted illness, for me and for a lot of others, it was good to be able to tell him directly how much I owed him. But beyond the warm, hospitable, humorous and hugely energising individual we knew, Jan was profoundly committed to-indeed lived - a programme of sociolinguistics that he often traced to the writings of Dell Hymes, the founder of Language in Society. ${ }^{1}$ A number of this programme's core elements were spelled out in the introduction to Hymes' ground-breaking 1969 collection, Reinventing Anthropology, a 'book... for people for whom "the way things are" is not reason enough for the ways things are, who find fundamental questions pertinent and in need of personal answer' (1969:7). For my account of the value and vitality that Jan brought to sociolinguistics, I have borrowed from the title of Hymes' introduction, 'The use of anthropology: Critical, political, personal' and, as well as citing some of Jan's own words, I also draw on the reflections of others ${ }^{2}$ as evidence of the vigour, clarity, and coherence with which he articulated a practice and purpose for work on language in society.

Jan's colleague, Sjaak Kroon, has summarised very well some of the facts of Jan's working life, moving into his contribution and style of working:

Jan Blommaert was born in Dendermonde, Belgium in 1961 and grew up in Brussels. He got his doctorate in African Philology and History at Ghent University in 1989 where he also was a Professor of African Linguistics and Sociolinguistics from 1997 to 2005, after a period as Research Director for the International Pragmatics Association in Antwerp. Then he moved to the Institute of Education, University of London as a Professor and chair of Languages in Education. In 2007 he was appointed Professor of Language, Culture and Globalization at the Department of Culture Studies, School of Humanities and Digital Sciences at Tilburg University where he in 2008 became the Director of Babylon, Center for the Study of Superdiversity. In addition, he held fellowships and visiting professorships at Gerhard-Mercator University Duisburg, University of Pretoria, University of Chicago, University of Jyväskylä, Beijing Language and Culture University, Hellenic American University, and the University of the Western Cape. ...

Between 2005 and 2010 Jan wrote three books that I once heard him refer to as a trilogy: Discourse (2005), Grassroots Literacy (2008) and The Sociolinguistics of Globalization (2010[a]). These books fundamentally changed our field from a sociolinguistics of stability into a sociolinguistics of mobility, dealing with all the complexities that processes of globalization and superdiversity bring to language, culture and society. ...

(C) The Author(s), 2021. Published by Cambridge University Press. This is an Open Access article, distributed under the terms of the Creative Commons Attribution licence (http://creativecommons.org/ licenses/by/4.0/), which permits unrestricted re-use, distribution, and reproduction in any medium, provided the original work is properly cited. 0047-4045/21 $\$ 15.00$ 
In recent years, Jan added a new perspective to his work: the online offline nexus. Titles like Durkheim and the Internet (2018) and Online with Garfinkel ([Blommaert, Szabla, Maly, Procházka, Ying, \& Kunming] 2019) bear witness of this new focus in which he used contemporary sociolinguistic insights to develop a new sociological imagination, exploring how we construct meaning and operate in online spaces, and what the implications of this are for offline social practice. This online turn was coproduced with many colleagues and $\mathrm{PhD}$ students who as of 2016 produced doctoral dissertations on a variety of topics related to online offline practices. ...

Over the course of his career, Jan introduced or dealt with concepts like discourse, voice, repertoire, ideology, scale, indexicality, superdiversity, chronotopicity, interaction, accent, supervernacular, ethnographic linguistic landscaping, grassroots literacy, genre, intertextuality, framing, multimodality, the online offline nexus - to name a few-[and] added to their development but always left the opportunity for others to engage, to contribute, accept, or reject his proposals. (Kroon 2021)

The opportunity for others to engage, contribute, accept, or reject. In Jan's own retrospection, 'discussion and brainstorm were my favourite activities; they were in the most literal sense the ludic, fun, pleasure dimensions of academic life' (Blommaert 2020). And talking to him was often unforgettable, both in and outside university environments: 'it was only one sentence, but it made all of my observations suddenly fall into place' (Ico Maly 2021a); 'none of his stuff was boring. He had a way of making things sound crisp. Debatable. And transferable' (Tom van Hout 2021); 'while in the workshop, things would happen extraordinarily fast and you'd look back and realise their productivity' (Jim Collins 2021); 'you told him a story and he turned it into theory.... Everything he said was so quotable' (Panayiota Charalambous 2021; Paty Paliokosta 2021); 'I will never forget the moment when he broke the frame of teaching, with humour and high performance... There were simply layers upon layers to be learnt from that moment' (Cathy Kell 2020); 'every single, however brief, interaction with Jan felt like a profoundly transforming and learning experience. The trajectory was always of the following kind: at first, I would resist, be mystified, and in some disbelief vis-à-vis his ideas... only to subsequently find it as one of the most powerful treatments of the subject' (Alexandra Georgakopoulou 2021); 'all of us got on the train back to London. A climate of intellectual debate but also of humor and camaraderie was immediately established, [Jan contributing] substantially with two qualities - intellectual vivacity and an ability to have a good time with colleagues' (Anna De Fina 2021); 'brainstorming with Jan was one of the great privileges of working with him, and it often took place in the least obvious of times and spaces. During walks and drives, while waiting for trains' (Piia Varis, p.c. 2021);

For five years we commuted from Belgium to Tilburg. 'Merxem, 8:15h.' he would text me the night before. After picking him up, we discussed our analyses, shared our incomprehension about the state of our country and the world, criticized the assumptions in journalists' questions and the ubiquitous dilettantism in the public sphere. We discussed unwritten books, research projects and individual ideas. We planned our dream program. We expressed our frustrations, but above all we roared with laughter at regular intervals. There was always the commitment, the drive, and the dedication. There was also the confirmation of his erudition - at times it seemed as if Jan had read everything. ${ }^{3}$ That, too, was the duty of the academic. ${ }^{4}$ (Maly 2021a) 
These accounts point to Jan's erasure of the lines between scholarship and living, operating with a reflexive habitus that Sirpa Leppänen also experienced in Jyväskylä: 'His extensive reading, combined with his extraordinary ability to crystallize complex concepts and theorizations and to show their relevance to the empirical study of language and communication,... opened up new ways for us to do research - to live a researcher's life. He himself was an embodiment of such a life.' (Leppänen 2021). And in Jan's own formulation, what 'still persuades people to choose a career in research' is 'the freedom to unthink what is taken to be true, self-evident and well-known and to re-search it, literally, as in "search again". It is the FREEDOM OF DISSIDENCE- a thing we often hide, in our institutionalized discourses, behind the phrase "critical thinking". I see dissidence as a duty in research, and as one of its most attractive aspects' (Blommaert 2020).

This dissidence was infinitely more than just a quest for novelty. It was grounded in a deep knowledge of classical social science and linguistics: 'to understand what linguists do today, we need to historize it, look back in time and understand where it comes from. Jan writes: "Historicizing epistemologies and methodologies is a prerequisite for critique. If we wish to improve particular kinds of analysis, it is essential that we remember where the tools for such an analysis come from, in what kind of épistème they are grounded, and what kind of ideological load they carry" (2013:6)' (Ana Deumert 2021). It was disciplined by an exceptionally 'keen capacity for the observation of minute linguistic and interactional phenomena' (De Fina 2021). And it was driven by the conviction (which he attributed to Hymes) that 'no social cause is served by poor work. Critical commitment demands a never-ending attention to theoretical and methodological improvement. If we believe that languages and their speakers should be equal, we have to understand their actual inequalities precisely and in detail' (Blommaert 2009b:242, 2010b:686). But, he insisted,

when you set your research program,... [m]ake sure it includes an acute eye for change within your field. That means that you will have to re-brand yourself like five, six times in your career, like I had to learn about social media very late in my career... [we] need to speak to reality. Well, reality changes. The bastard changes all the time; society refuses to sit still. Well, we have to adjust to that and incorporate it in our research. (Blommaert \& Van Der Aa 2020:6)

Combining erudition, analytic acuity, and an ingrained sense that 'science can never be submissive, never be a matter of "following a procedure" or "framework" (Blommaert 2020), Jan had a charisma that propelled him into "celebrity culture in academia'. In the end, though, he stepped back from this experience, speaking critically of an emerging system in which

rockstar headliners bring... their greatest hits in front of an audience of poorly paid struggling academics who spent their personal holiday budgets purchasing a ticket for such events. Little truly valuable intellectual work is going on there... this new culture took away and delegitimized a previous culture, one of collegial dialogue, collaboration, slowness, time to think, to reflect and to doubt, periods of invisibility and absence from public stages - because one was doing some serious bit of research, for instance. (Blommaert 2020) 
Quite rightly, he recognised his capacity to inspire, which was something that I often experienced myself, that I repeatedly saw with doctoral students at our linguistic ethnography summer school, and that others have amply affirmed: 'little did I know then that his answer would change my life forever' (Maly 2021a); 'for me as for so many others, encountering Jan was truly a life-changing experience' (Rob Moore 2021); 'I remember reading this seminal work for the first time and being blown away... The book literally changed my academic trajectory' (Christian Chun 2021); he 'pushed me to be a better version of myself. He spoke highly of his colleagues and PhD students. And drove them to excel' (Van Hout 2021); 'I remember Jan telling us about Stakhanovism; which means: doing more than is expected from you - and indeed, being ambitious and raising the bar continuously; that is one of the first life lessons Jan taught me' (Annelies Verdoolaege 2021); he 'showed me - then a young academic at the beginning of her professional career-what academia and scholarship could be, the futures that were possible and our own responsibility in making them happen' (Deumert 2021). But instead of seeing this ability as a personal trait of the kind one might (pseudo)modestly disclaim, Jan saw inspiration as an essential element in academic practice. Inspiration, he said,

is the force that suddenly opens areas and directions of thought, shows the embryo of an idea, offers a particular formulation capable of replacing most others, and so forth. Inspiration is about THINKING, it is the force that kickstarts thinking and that takes us towards the key element of intellectual life: IDEAS... [I]n our own practices, we should perhaps also try, consciously and intentionally, to inspire others. I mean by that: we should not offer others our own doctrines and orthodoxies. We should offer them our ideas - even if they are rough on the edges, unfinished and halfsubstantiated — and explain how such ideas might fertilize - not replace - what is already there. I have quite consistently tried to inspire others, and to transmit to them the importance I attached to inspiration as a HABITUS in work and in life. (Blommaert 2020)

Inspiration as academic practice had an essential corollary: 'creating communities of academics from all corners of life' (Najma Al Zidjaly 2021), going 'to great lengths to make you feel like you belonged in academia' (Van Hout 2021). 'One thing remained constant, wherever Jan went, or whoever you talked to about him; he was generous and set up a system of democratic knowledge sharing wherever he went' (Van der Aa 2021). He used his 'preternatural gift for communication to foment scholarly collaboration on a global scale, building sustainable networks that brought together researchers from around the world to work on shared problems' (Moore 2021). 'He always kept in touch with people with whom he had common interests through a stream of initiatives that were aimed at creating networks of collaboration and debate. Jan always was a team player and a proponent of collective initiatives' (De Fina 2021). I can think of at least four such initiatives (with names) that I have participated in, and each has had a major impact on the direction and tenor of my work. ${ }^{5}$ But the democratic knowledge sharing with people from all corners - what he and Van der Aa called 'epistemic solidarity' (Van der Aa \& Blommaert 2015) — extended further, well beyond the academy. 
In one of his last publications, he wrote,

In my life whenever I doubted the importance of what I was doing academically (and that happened very frequently, believe me), the answer was given by my activism. And the answer was: because THEY need it, these activists, trade union people but also school teachers. I gave lectures all through my life to non-academic audiences ranging from trade unions to individuals and organizations across the social spectrum, and I was everywhere. I was literally everywhere. I also wrote fifteen small books in Dutch for which I never got any academic recognition of course, but they were vulgarizing small books that were used in trade unions, in-service language programs and so on. So the activists were also my audience and THEY told me my academic work was valuable. They told me to continue; they told me to do more; they asked me questions that then became like priorities in research for me. (Blommaert \& Van der Aa 2020:6)

In consequence, in March 2020,

when he broke the news that he was ill, he was immediately overwhelmed by the many messages he received on his Facebook, Academia page, Twitter, and email. In Belgium... hundreds of exstudents, civil society workers, activists, journalists, politicians, and unionists would thank him for his many contributions to society in Facebook posts on his wall. He was not only personally overwhelmed by it all or thankful, he saw it as proof that 'HIS PUBLICATION STRATEGY WORKED'. A strategy he coined 'knowledge activism' and focused on open publishing and giving back knowledge to other academics and society in general. (Maly 2021b:1)

\section{Knowledge activism, of course, generated conflict:}

The Dutch version of Debating Diversity - Het Belgische Migrantendebat (Blommaert and Verschueren, 1992)... was not only self- published because no publisher wanted it, it was also politically explosive. This counter-hegemonic voice came with a price tag... the rector [tried] to silence him and Verschueren, and journalists, politicians and even academic colleagues tried to denigrate them. This was not a one-time occurrence. Later when Verschueren and he published a new book on antiracism (Antiracisme Blommaert and Verschueren, 1994), authors from the same publishing house pushed their publisher to withdrew it from the stores. Throughout his life he has received 'tons of shit' to quote him. (Maly 2021b:2)

But he wasn't intimidated, and his knowledge activist critique also covered the counter-productive and anti-democratic structures of academic production.

So, for example, in the course of our language and superdiversity collaboration, we submitted an unsuccessful application to the EU's Horizon 2020 funding programme, spending hundreds of hours and several international trips worth several thousand Euros preparing the bid. Jan delivered the home truth:

After submitting, we heard that a total of 147 applications had been received by the EU. And that the EU will eventually grant $2-$ TwO- projects. In a rough calculation, this means that the chance of success in this funding line is $1.3 \%$; it also means that $98.7 \%$ of the applications -145 of them, to be accurate-will be rejected... The paradox is clear: by going along with the stampede of competitive external funding acquisition, ALMOST ALL universities across the EU will LOSE not just money, but extremely valuable research time for their staff. Little academic improvement will be made, and little progress in science, if doing actual research is replaced by writing grant proposals with an almost-zero chance of success. And as long as academics and academic units are told that success or failure in getting EU funding (with success rates such as the one mentioned here known in advance) is a criterium for determining their academic quality, gross injustice will be committed. People will be judged inadequate, mediocre or simply poor academics because they failed to get the benchmark funding - awarded, as we saw, on grounds that have little to do with academic quality assessments of applications. (Blommaert 2016:2-4) 
Much more generally, early 'experiences in African universities made me very much aware of the existence of several academic worlds, not the idealized one "academic community" sometimes invoked as a trope', 6 and 'inequality became the central theme in my work AND ACADEMIC PRACTICE from the first moment I embarked on it' (Blommaert 2020, my emphasis):

I disliked and dislike - intensely - the development of academic industrial culture that I was witness to throughout my career, with almost-totalized individualization of academic work and performance measurement, with constant inter-individual competition driving young and vulnerable colleagues to extreme and dangerous levels of stress and investment in work rather than life, and with managers emphasizing — without any burden of evidence - that the 'single-authored journal paper' (published, evidently, behind a huge paywall) is the pinnacle of academic performance and the gold standard for measuring the 'quality' of an individual researcher. (Blommaert 2020)

Where there was institutional flexibility, Jan could work very productively with university managers (and at the University of the Western Cape, he 'worked in very close concert with... the most inspiring and energizing team of academic leaders I had ever met' (Blommaert 2020)). He 'tirelessly discussed with his colleagues not only the work itself but also HOw WE DO THE WORK as academics... [M]any a younger scholar, myself included, [is] indebted to him for valuable lessons on how to be an academic in neoliberal academia and the ways in which resistance is not, after all, futile' (Varis, p.c. 2021). And maybe Jan's clearest intervention in the practicalities of scholarship was in academic publishing, an industry which in general, he argued, 'has become a disgrace and is an obstacle to science, not a facilitator (let alone an indispensable actor)' (Blommaert 2020). Here he embraced open source publication, 'opening up the closed system of academic publishing to professionals and students... who cannot afford to buy them' (De Fina 2021), to 'scholars from the Global South who can't afford the commercial versions of my work' (Blommaert 2020), and to people active in civil society (Maly 2021a). He co-founded Tilburg Papers in Culture Studies ${ }^{7}$ and Diggit $^{8}$ (an online magazine providing an alternative platform for information exchange and debate on digital culture, globalisation, and the arts), and he posted prolifically in blogs, ${ }^{9}$ Facebook, tweets, and videos. On academia.edu, ${ }^{10}$ his papers have over a quarter of a million views (an astonishing figure), ${ }^{11}$ and 'you could always find his books first as 'working paper' previews somewhere for free, often to the annoyance of his publishers' (Van der Aa 2021). At the same time, these practical interventions developed in continuous dialogue with theory and analysis, in which he opened 'a new frontier for the analysis of political discourse with his... reflections on communication in the post-digital world' (De Fina 2021), generating 'new insights into notions of communities, user identities, and genres' online (Georgakopoulou 2021).

In sharp contrast to Hymes' work, which Jan deemed generally 'tough reading' (2010b:685), Jan's writing was 'always didactic in nature[, taking] the reader, viewer, or student by the hand' (Maly 2021a), even though it sought to 'give them a glimpse of what lies beyond, of the open terrain for which my writings 
offered no road map, but which my writings could help them to detect as open for exploration" (Blommaert 2020). "Write to be read" and "write a paper you'd like to read yourself" were pieces of advice Jan gave to all of his younger colleagues' (Varis, p.c. 2021). But despite this difference, Hymes' writing breached the traditional front- and back-stage boundary in academic work very much like Jan's, and it brought the practices, people and institutions producing analysis into the spotlight alongside the objects being studied, articulating a reflexive methodological programme that embraced intellectual inheritance and practical organisation alongside theory and empirical description (Blommaert 2009a; Rampton 2009). In this way, both scholars innovated with channels of publication, Blommaert exploring the affordances of the internet, Hymes setting up Language in Society, sociolinguistics' first journal. Like Blommaert, Hymes' writing questioned university structures and deferential science, asking whether the future of the graduate department in anthropology would 'prove to have been chrysalis or coffin' (Hymes 1969:7), declaring that '[p]roductive scholars know that problems lead where they will and that relevance commonly leads across disciplinary boundaries. Yet many an insecure academic compensates for [their] own lack or loss of intellectual [potency] by making it difficult or impossible for students and junior colleagues to benefit from theirs' (Hymes 1969:44-45). And Jan's undergraduate teaching achieved something parallel to what Hymes said could be ' $[\mathrm{t}]$ he greatest contribution of anthropology departments[: T]o send into the world many lawyers, historians, activists, workers for various institutions and agencies, well training in anthropological work' (Hymes 1969:57). 'From day one, [Jan] gave me and my former fellow classmates at Ghent University glasses through which to look at the world around us... Glasses which we still carry with us, and that allow us see the world, its people and their interactions in a totally different way... [S]ending us to do ethnographic fieldwork in the most intercultural areas of Ghent, we came back with a box full of data gathered that, as [he] had intended, completely altered our relationship with space, place and identity' (Fie Velghe 2021).

But it is obviously a driving commitment to the development of ethnographic sociolinguistics that connects Blommaert to Hymes' work most closely, integrating the productivity of two brilliant and innovative minds in a distinctive, powerful and sustainable intellectual programme. As Maly notes, Jan 'always started from the idea that language is the architecture of society. Language, according to him, is always socially loaded. It has a history of use, and is used in society. It is not only the stuff that makes us social, it also is socially and politically consequential for humans' (Maly 2021b:3). Throughout his career, Jan took the details of linguistic practice as the point of departure for acute analyses that demonstrated how, for example, 'the combination of linguistics and ethnography' can produce a 'layered, multi-scalar and empirically grounded understanding of ideology [that] is perhaps one of the most sophisticated ones in current social science' (Blommaert \& Rampton 2011:11). The depth and range of his reading made him a compelling advocate of sociolinguistics for people in other disciplines (as in publications like 
Durkheim and the Internet (2018b), strap-lined On Sociolinguistics and the Sociological Imagination). And again, this was something that Jan could tie to Hymes' oeuvre: 'This is how I prefer to remember him and to use Hymes' legacy: as a framework that enables the incorporation of a vast field of social-scientific angles, tools and instruments. Hymesian sociolinguistics' (Blommaert 2010b:683).

A fortiori, however, the strands in Jan's practice cohere as the enactment of an approach to ethnography that he associated with Hymes. He scorned the idea that ethnography was just fieldwork-plus-descriptions-of-'context', and actually saw Hymes' writing as 'a victim of such reductions' (Blommaert 2009c:260). Instead, ethnography is 'a general programmatic PERSPECTIVE on social reality and how real subjects, in real conditions of everyday life, possessed by real interests, make sense of reality' (Blommaert 2018a:ix, original emphasis). And as well as 'including ontology and an epistemology', Hymesian ethnography is 'a democratic science', a counter-hegemonic politics of knowledge (Hymes 1980, 1996; Blommaert 2009c:260-61 et passim; Blommaert \& Dong Jie 2020:12). Indeed, beyond the elements of ethnography that people can develop through study and practise, beyond its programmatic features, ethnography - at its most reflexiveseemed to be in Jan's case a deeply ingrained, personal disposition. 'He preached that theory always flows from specifics, that case studies aren't simply illustrations but are the raw material which allows for theorising' because he was 'an ethnographer AT HEART' (Philip Seargeant 2021, emphasis added). He wrote about globalisation because he lived it every day, ${ }^{12}$ and not even the most pressing personal circumstances could stop the productivity of his participant-observation. For about a year late on in his career, he experienced burnout, "but hearing Jan talk about how it blindsided him and made him feel utterly incompetent and vulnerable was an eye-opener... Jan talked about lying fallow, taking back control, slowing down science, and saying no to reproductive, gap-filling research... He normalized vulnerability and fallow time in the interest of science' (van Hout 2021). Many of the quotations in the text here draw on what Jan wrote after his diagnosis with terminal cancer, and for many, this 'was an important sign to other scholars, that one does not become a better academic by hiding the difficult sides to life' (Martha Karrebæk 2021). ${ }^{13}$

Critical, political, personal. Like all of us, Jan was unique, and his exceptional productivity was founded in the particularity of his marriage to Pika Colpaert, who 'is the reason why I have been able to work the way I have,... the management who did almost all the administrative and organizational work necessary for my development' (van Schijndel 2020). In that respect, the best we can do is simply rejoice that sociolinguistics was the focus for so much of Jan and Pika's extraordinary endeavour. But even though Jan was the exponent sans pareil and few can hope to match his brilliance, his originality, and his mobilising power across teaching, research, AND activism, he affirms sociolinguistics as a programme with pedigree, purposes, and practices that he encourages - or rather, works to inspire - a great many others to join, as best they can. For some, Jan's life stands for 


\section{JAN BLOMMAERT AND THE USE OF SOCIOLINGUISTICS}

the academic as public intellectual. The academic who is more than an employee in a diploma factory, but an academic who imagines himself or herself as a cornerstone of democracy. An academic who sees their research, their teaching position and social demonstration as their task, one that should be taken on with care and commitment... It is high time for academics to examine the structures that curtail that social role, so that we can once again take up the role of public intellectual to the fullest. (Maly 2021a)

\section{For others,}

still more than a teacher, I think, Jan was a writer. He told me once that he tried every day to devote some of his time to writing, early in the morning before day-to-day business caught him, late at night, or in time stolen from so many holidays. I think it is in writing that Jan found his main raison d'être, the final fulfillment of wanting to share his - as he himself said in an interview, often unfinishedthoughts and ideas and challenge his readers, students and colleagues alike, to discuss, complete, reject or elaborate on them, ultimately leading to a multitude of collective (open-access) authorships. (Kroon 2021)

Plainly, the lines of uptake and engagement are open and unsettled, but wherever the reverberations, for me as for others, Jan stands as the shining contemporary validation of sociolinguistics.

\section{N O T E S}

${ }^{1}$ Rather than speaking of Hymes as a person, it was what Hymes wrote that Jan aligned with. He recognised the problems and conflicts associated with Hymes (Blommaert 2009c:242), but separating the person from the work, he insisted that few 'have left an oeuvre of such complexity and richness; this oeuvre deserves profound exploration and examination. There is a danger, given the animosities that...surround Hymes, that this... will be neglected. We would not do ourselves good service if this would happen' (2009c:242). This is also the position that I take in what follows.

${ }^{2}$ Most of these were either offered at Jan's funeral on 16 January 2021, at the Memorial Event for Jan Blommaert on 6 February 2021 coordinated by Karel Arnaut, Jenny-Louise Van der Aa, and Piia Varis, or published in Diggit, the digital magazine set up by Jan, Ico Maly, Sjaak Kroon, and others at Tilburg University.

${ }^{3}$ 'I read massively all through my life. And while part of that reading was 'just' reading, another part was STUDYING. Most of my career, I was involved in some kind of study, collecting and selecting writings from which I wanted to draw advanced insights, useful for the research projects I was engaged in. I studied, for instance (and the list is not complete), structuralism, existentialism, phenomenology, arcane things such as the works of Rudy Botha on Chomsky and the Functional Grammar attempts of Simon Dik, Talmy Givon and M. A. K. Halliday; but also the entire oeuvre (or, at least, most of what I could get) of Michel Foucault, Carlo Ginzburg, Bakhtin, Freud, Durkheim, Simmel, Parsons, Eric Hobsbawm, E. P. Thompson, Pierre Bourdieu, Charles Goodwin, Dell Hymes, Michael Silverstein, Erving Goffman, Aaron Cicourel, Harold Garfinkel, Anne Rawls, Fernand Braudel, J. K. Galbraith, Immanuel Wallerstein, Arjun Appadurai and several others. I studied Marx and Marxism in its very diverse varieties, Rational Choice, Macchiavelli, Darwin, G. H. Mead's work and influence, Dewey, Paolo Freire, Ngugi wa Thiong'o, Okot p'Bitek, Walter Rodney, Issa Shivji and quite a bit of African political theory from the 1950, 1960s and 1970s. In order to understand a lot of that, I had to study the works of Mao Zedong and the history of the Cultural Revolution in China. And so on, and so forth.' (Blommaert 2020).

'Most practitioners of sociolinguistics are reasonably competent at the analysis of language; very, very few have brought to their work the deep knowledge of social theory - from Durkheim and Marx to new and emerging work - that Jan possessed, and was constantly expanding, thanks to his wide reading and insatiable curiosity.' (Moore 2021) 


\section{BEN RAMPTON}

${ }^{4}$ 'I grew up and studied in the welfare-state educational system of Belgium, and given the modest socio-economic status of my family, I would probably never have received higher education in other, fee-paying systems. I'm very much a product of a big and structural collective effort performed by people who did not know me - taxpayers - and regardless of who I was. I am a product of a democratic society. I remained extremely conscious of that fact throughout my adult life, and my political stance as a professional academic has consistently been that I, along with the science I produce, am a RESOURCE FOR SOCIETY, and SHOULD GIVE BACK TO SOCIETY what society has invested in me.' (Blommaert 2020; original emphases)

${ }^{5}$ Language, Power and Identity 1999-2004; the Ethnography, Language, \& Communication doctoral training programme (2007-); the International Consortium on Language \& Superdiversity 2009-2017; Multilingualism in Society, based at the University of the Western Cape.

${ }^{6}$ As David Parkin (p.c. 2021) notes, it is important 'to highlight Jan's early work on Swahili in Tanzania because... it provided a foundation for many of the later accomplishments outside Africa for which he is even better known globally... His brilliant sociolinguistic analysis of ujamaa ('African socialism') as humanitarian philosophy fitted the political views which informed much if not most of his subsequent work.'

${ }^{7}$ https://www.tilburguniversity.edu/research/institutes-and-research-groups/babylon/tpcs

${ }^{8}$ https://www.diggitmagazine.com/

${ }^{9}$ https://www.researchgate.net/publication/346422479

${ }^{10}$ https://tilburguniversity.academia.edu/JanBlommaert

${ }^{11}$ As of 24 February 2021, his writing has over 36,000 citations and an h-index of 75 (Harzing's Publish or Perish — an app with a name that Jan would recognise but inveigh against!).

${ }^{12}$ Seeing a Belgian write about cricket might make me raise my English eyebrows, but only for a moment until I read: 'One evening recently, I found myself in my local Antwerp night shop along with three other people: the Indian owner, a man from Pakistan and one from Sri Lanka. In a matter of seconds, I got involved in an intense discussion on the 2019 Cricket World Cup.' (Blommaert 2019)

${ }^{13}$ As several people noted at his memorial service, 'you could share dark moments' with Jan (Charalambous 2021); he 'was not afraid of supporting others when they went through difficult moments in time' (Karrebæk 2021).

\section{R E F E R E N C E S}

Al Zidjaly, Najma (2021). Contribution to Memorial Event for Jan Blommaert, 6 February. Blommaert, Jan (2005). Discourse: A critical introduction. Cambridge: Cambridge University Press. - (2008). Grassroots literacy. London: Routledge. (ed.) (2009a). On Hymes. Special issue of Text \& Talk 29(3). (2009b). On Hymes: Introduction. In Blommaert 2009a, 241-43. (2009c). Ethnography and democracy: Hymes' political theory of language. In Blommaert 2009a, 257-76.

- (2010a). The sociolinguistics of globalization. Cambridge: Cambridge University Press. (2010b). Dell H. Hymes (1927-2009). Journal of Sociolinguistics 14(5):682-86. (2013). From fieldnotes to grammar: Artefactual ideologies of language and the micromethodology of linguistics. Tilburg Papers in Culture Studies 84. Online: https://www.tilburguniversity. edu/research/institutes-and-research-groups/babylon/tpcs.

(2016). Rationalising the unreasonable: There are no good academics in the EU. Working Papers in Urban Language \& Literacies 184. Online: https://www.academia.edu/19954607.

(2018a). Dialogues with ethnography: Notes on classics, and how I read them. Bristol: Multilingual Matters. [Also published as TPCS 138.] Online: https://www.academia.edu/19342202/.

(2018b). Durkheim and the internet: On sociolinguistics and the sociological imagination.

London: Bloomsbury. [Also available as Working Papers in Urban Languages \& Literacies 204.] Online: https://www.academia.edu/30719475. 


\section{JAN BLOMMAERT AND THE USE OF SOCIOLINGUISTICS}

(2019). Interested in globalisation? Watch cricket. Diggit Magazine 25/06/19. Online: https:// www.diggitmagazine.com/column/cricket.

(2020). Looking back: What was important? Ctrl+Alt+Dem. Online: https://www. researchgate.net/publication/346422479.

— \& Dong Jie (2020). Ethnographic fieldwork: A beginner's guide. 2nd edn. Bristol: Multilingual Matters.

— \& Ben Rampton (2011). Language and superdiversity. Diversities 13(2):1-21.

; with Malgorzata Szabla; Ico Maly; Ondřej Procházka; Lu Ying; \& Li Kunming (2019). Online with Garfinkel: Essays on social action in the online-offline nexus. Tilburg Papers in Culture Studies 229. Online: https://www.tilburguniversity.edu/sites/default/files/download/TPCS_229-Blommaert.pdf.

—_ \& Jenny-Louise Van der Aa (2020). Jan Blommaert on education: Teaching, research and activism. Working Papers in Urban Language and Literacies 278. Online: https://www.academia. edu/44725342.

_ \& Jef Verschueren (1992). Het Belgische Migrantendebat. Antwerp: International Pragmatics Association (IPrA). Online: https://www.researchgate.net/publication/338671165_Het_ Belgische_Migrantendebat.

— \& \& (1994). Antiracisme. Antwerp: Hadewijch.

_ \& _ (1998). Debating diversity: Analysing the discourse of tolerance. London: Routledge.

Charalambous, Panayiota (2021). Contribution to Memorial Event for Jan Blommaert, 6 February.

Chun, Christian (2021). My tribute to Jan Blommaert. Diggit Magazine 07/01/21. Online: https:// www.diggitmagazine.com/articles/my-tribute-jan-blommaert.

Collins, Jim (2021). Contribution to Memorial Event for Jan Blommaert, 6 February.

De Fina, Anna (2021). Jan Blommaert, the trail blazer. Diggit Magazine 07/01/21. Online: https:// www.diggitmagazine.com/articles/jan-blommaert-trail-blazer.

Deumert, Ana (2021). Semiotic future: Celebrating Jan Blommaert's radical scholarship. Diggit Magazine 11/01/21. Online: https://www.diggitmagazine.com/column/semiotic-futures-celebratingjan-blommaert-s-radical-scholarship.

Georgakopoulou, Alexandra (2021). Contribution to Memorial Event for Jan Blommaert, 6 February.

Hymes, Dell (1969). The use of anthropology: Critical, political, personal. In Dell Hymes (ed.), Reinventing anthropology, 3-82. New York: Pantheon Books.

- (1980). Ethnographic monitoring. In Dell Hymes, Language in education: Ethnolinguistic essays, 104-18. Washington, DC: Centre for Applied Linguistics. Online: https://files.eric.ed. gov/fulltext/ED198745.pdf.

(1978/1996). What is ethnography? In Dell Hymes, Ethnography, linguistics, narrative inequality, 3-17. London: Taylor \& Francis. Online: https://www.academia.edu/36884832/.

Karrebæk, Martha (2021). Contribution to Memorial Event for Jan Blommaert, 6 February.

Kell, Cathy (2021). Tribute to Jan Blommaert. Email circulated 11 January 2021.

Kroon, Sjaak (2021). In memory of Jan Blommaert. Diggit Magazine 08/01/21. Online: https://www. diggitmagazine.com/articles/memory-jan-blommaert.

Leppänen, Sirpa (2021). Contribution to Memorial Event for Jan Blommaert, 6 February.

Maly, Ico (2021a). Tribute to Jan Blommaert as public intellectual. Diggit Magazine 08/01/21. Online: https://www.diggitmagazine.com/articles/tribute-jan-blommaert-public-intellectual.

— (2021b). Jan Blommaert (1961-2021). Discourse \& Society. Online: https://doi.org/10. $1177 / 0957926521992689$.

Moore, Robert (2021). Eulogy at Jan Blommaert's Funeral, 16 January.

Paliokosta, Paty (2021). Facebook post, 7 January.

Rampton, Ben (2009). Dell Hymes' visions of enquiry. In Blommaert 2009a, 359-69.

Seargeant, Philip (2021). Jan Blommaert in Bloomsbury: Recollections of Jan's years in London in the mid-noughties. Diggit Magazine 05/01/21. Online: https://www.diggitmagazine.com/articles/Janblommaert-bloomsbury. 
Van der Aa, Jenny-Louise (2021). Jan Blommaert's struggle. Diggit Magazine 11/01/21. Online: https://www.diggitmagazine.com/column/jan-blommaerts-struggle.

— \& Jan Blommaert (2015). Ethnographic monitoring and the study of complexity. Working Papers in Urban Language \& Literacies 150. Online: https://www.academia.edu/1047150.

van Hout, Tom (2021). Farewell, Jan Blommaert. Diggit Magazine 12/01/21. Online: https://www. diggitmagazine.com/articles/farewell-jan-blommaert.

van Schijndel, Mariska (2020). Jan Blommaert: 'You have the feeling that you have no grip on your body. That is the definition of cancer'. Univers. Online: https://universonline.nl/nieuws/2020/ $11 / 19 /$ jan-blommaert-you-have-the-feeling-that-you-have-no-grip-on-your-body-that-is-the-definitionof-cancer/.

Velghe, Fie (2021). Eulogy at Jan Blommaert's Funeral, 16 January.

Verdoolaege, Annelies (2021). Contribution to Memorial Event for Jan Blommaert, 6 February.

(Received 18 March 2021)

Address for correspondence:

Ben Rampton

King's College London

School of Education, Communication \& Society FWB-WBW, Waterloo Road, London SE1 9NH, UK ben.rampton@kcl.ac.uk 